\title{
Multi-Disciplinary Discharge Coordination Team to Overcome Discharge Barriers and Address the Risk of Delayed Discharges
}

\author{
Halah Ibrahim (1D) ${ }^{1,2}$, Thana Harhara $\mathbb{D}^{2}$, Syed Athar ${ }^{2}$, Satish C Nair $\mathbb{D}^{3}$, Ahsraf $M$ Kamour $\mathbb{D}^{2}$ \\ 'Department of Medicine, Khalifa University College of Medicine and Health Sciences, Abu Dhabi, United Arab Emirates; ${ }^{2}$ Department of Medicine, \\ Sheikh Khalifa Medical City, Abu Dhabi, United Arab Emirates; ${ }^{3}$ Department of Academic Affairs, Tawam Hospital, College of Medicine, UAE \\ University, Al Ain, United Arab Emirates \\ Correspondence: Satish C Nair, Department of Academic Affairs, Tawam Hospital, Post Box 15258, Al Ain, United Arab Emirates, Tel +97|37074739, \\ Email satchi2000@outlook.com
}

Background: Delays in hospital discharge occur when patients are medically cleared but continue to remain hospitalized. Discharge delays can result in reduced levels of treatment, placing patients at risk of functional decline, falls and hospital-related adverse events. The Institute of Medicine has highlighted timely, efficient, and safe hospital discharge as a marker for quality care. Hospitals, however, are often unable to meet discharge targets. Research has shown improvements in discharge planning through system-level approaches that integrate health care and social work. The purpose of this study is to describe the development and implementation of a multidisciplinary team intervention to overcome discharge barriers for patients with prolonged hospitalization. We also evaluated the impact of the intervention on length of stay, readmission rates and care team satisfaction and morale.

Methods: A multidisciplinary discharge coordination team met weekly to proactively raise and resolve patient-related discharge issues for all patients admitted to the general medicine wards. Members included hospitalists, case managers, social workers, hospital finance representatives, and patient representatives. One of the hospital physicians facilitated the meetings.

Results: Barriers to discharge included patient and family reluctance to discharge, medical delays in performing diagnostic tests or procedures, long-term care facility acceptance delays, and prolonged wait times for insurance approvals. Our multipronged approach decreased length of stay in our delayed discharge patient population from 15.45 days to 9.04 days, a $41.5 \%$ reduction, without an increase in readmissions. The healthcare team perceived the weekly multidisciplinary team meetings quite positively; $90 \%$ of respondents agreed that the meetings improved communication and increased their sense of support.

Conclusion: Our intervention was successful in improving hospital processes to overcome barriers to patient discharge. We believe that similar multidisciplinary meetings can be implemented in hospitals throughout the region to decrease risks of prolonged hospitalization and, ultimately, improve hospital efficiency and care delivery.

Keywords: discharge planning, discharge delays, length of stay, prolonged hospitalization, multidisciplinary team

\section{Plain Language Summary}

Hospitals worldwide often deal with patients who remain hospitalized after being deemed medically fit for discharge. This results in adverse consequences for patients, healthcare workers and the health system. We created a multidisciplinary discharge coordination team and implemented weekly meetings that included physicians, case managers, social workers, finance and patient representatives to proactively address discharge barriers. Our intervention successfully decreased length of stay in delayed discharge patients. The healthcare team had very positive perceptions of the intervention.

\section{Background}

The Institute of Medicine has highlighted timely, efficient, and safe hospital discharge as a marker for quality care. ${ }^{1}$ Inpatient length of stay is an important benchmark for patient care and administrative practice. Hospitals, however, are often unable to meet discharge targets. ${ }^{2}$ Delayed discharge is defined as the period of continued hospitalization, due to 
non-medical reasons, after a patient is deemed medically fit for discharge. ${ }^{2}$ Delayed discharge has many negative consequences. For patients, the risk of adverse events accrues during hospitalization, including increased risk of hospital acquired infections, medication errors, thrombotic events, and pressure ulcers. ${ }^{3}$ Patients with extended length of stay may also receive a reduced level of care, further increasing the risk of cognitive and functional decline. ${ }^{4}$ For the healthcare team, patients with prolonged hospitalization contribute to higher inpatient census and subsequent resource constraints, resulting in increased staff workload and stress. Delayed discharge also has important ramifications on the healthcare system. Increased length of stay affects inpatient flow through the hospital, increasing the number of patients boarding in the emergency department, delaying transfers within and between hospitals, ${ }^{5}$ and causing cancellation of elective procedures due to lack of bed availability. ${ }^{6}$ In addition, there are unmeasured societal costs resulting from prolonged hospitalizations. For example, family and friends often take on the role of "unpaid caregiver" to assist the patient during their hospital stay, leading to further loss of productivity. ${ }^{7}$

Delayed discharge is a global healthcare problem. A multi-institution study in Canada found that approximately 10\% of hospital beds were occupied by patients medically fit for discharge. ${ }^{8}$ Research in the United States shows that approximately $20 \%$ of hospital length of stay may be inappropriate. ${ }^{9}$ In the United Kingdom, the costs of delayed discharge are estimated to be $£ 100 \mathrm{~m}$ annually. ${ }^{10}$ As causes and solutions for prolonged length of stay may differ from one hospital to another, identifying and addressing local barriers to discharge can have important clinical and economic ramifications for all healthcare systems.

Hospitals have trialed several different initiatives to improve the efficiency of patient discharges, including implementation of discharge criteria for common diagnoses, use of communication boards, and computer applications to facilitate the discharge process, all with varying levels of success. ${ }^{11,12}$ Mathews et al, for instance, describe an electronic medical record prompt that identified the likelihood of a patient's next day discharge as red (unlikely), yellow (possible), or green (likely). ${ }^{11}$ Although the tool helped to facilitate discharges, it was reliant on the physicians to accurately predict and facilitate hospital discharges. Historically, the responsibility for discharge was placed primarily on the attending physician. This is problematic as physicians are often unable to resolve the complex systemic issues that lead to prolonged hospitalization. ${ }^{13}$ Previous research has shown improvements in discharge planning through system-level approaches that integrate health care and social work. ${ }^{14}$ For example, Meo et al implemented daily multidisciplinary discharge rounds with physicians, nurses and social workers, using an electronic tracking tool to standardize information. ${ }^{15}$ They noted a $21 \%$ reduction in length of stay without increased readmission rates. In another intervention conducted in a Veterans Health Administration hospital in the United States, a multidisciplinary escalation huddle was held daily to specifically address patients with delayed discharge, and included the leader of discharge rounds and the hospital's deputy chief of staff. The team reviewed discharge barriers and developed individualized care plans. ${ }^{16}$ In this case report, we describe the development and implementation of a multidisciplinary team intervention to overcome discharge barriers for patients with prolonged hospitalization. We evaluate the impact of the intervention on length of stay, readmission rates, and care team satisfaction and morale.

\section{Setting}

The United Arab Emirates (UAE) is a young nation, established 50 years ago as a federation of seven emirates. Over the past several decades, the country has experienced significant economic growth and expansion, and has invested substantially in its healthcare system. A major priority of the UAE national strategy is to improve the health of its citizens and the performance of its healthcare system. ${ }^{17}$ Recent health policies focus on addressing cost and quality challenges. ${ }^{17}$ Although published data is limited, a systematic review of health system reforms in the UAE noted few studies, with most focusing on processes, rather than outcomes. ${ }^{17}$ To our knowledge, this is the first study evaluating hospital discharge in the UAE. The methods of the study were carried out in accordance with the International Conference for Harmonization (ICH), and Good Clinical Practice, Declaration of Helsinki guidelines, and any other local and national guidelines from the Department of Health, Abu Dhabi, UAE. The study obtained research ethics approval from the Sheikh Khalifa Medical City Research Ethics Committee (RS-726). Participants required to complete the survey provided written informed consent. Waiver of written informed consents to review medical records was 
granted by the same Ethics Committee. No personal identifying information was collected for the patients, both subject privacy and patient data confidentiality were strictly adhered to in accordance with international and national guidelines.

This project was implemented at Sheikh Khalifa Medical City (SKMC), the largest government tertiary care hospital in Abu Dhabi, the UAE's capital. It is a 586-bed facility and a major referral center for the region. SKMC serves as a safety net hospital, providing emergency inpatient care for patients, regardless of insurance or immigration status. Patients are admitted through the emergency department, from the outpatient clinics, or referred from community hospitals. The general medicine service covers 140 beds. It is comprised of 8 teams, with a census of approximately 18 patients each. Teams are ward-based (geographic), and each ward has a dedicated case manager. In 2019, the average length of stay was 15 days, and the inpatient census on the general medicine service was consistently over capacity.

\section{Intervention (Figure I)}

In June 2020, hospital leadership convened a task force, comprised of hospital physicians and case managers, to review discharge processes and make recommendations. Through baseline interviews with stakeholders, including nurse managers, physicians, social workers and case managers, along with chart reviews, the task force identified prolonged hospitalizations as a major challenge. Task force members also identified the primary factors contributing to delayed discharge in our institution, namely (1) medical delays (procedures, imaging, subspecialty consultation), (2) disposition issues (equipment, home nursing and long-term care (LTC) facility acceptance), and (3) patient and family concerns (goals of care conversations, education, treatment disagreements).

To address these concerns, hospital leadership assembled a multidisciplinary discharge coordination team to meet weekly to proactively raise and resolve specific patient-related discharge issues. Members included hospitalists, case managers, social workers, hospital finance representatives, and patient representatives. Senior leadership fully supported the team members, and the department of medicine chair attended early meetings as a sign of support. One of the hospital physicians served as the facilitator for all of the meetings. In our hospital, case managers are nurses, who undergo a 3-month orientation and receive additional on-the-job training in discharge planning and utilization reviews. They must also pass the ANCC Nursing Case Management board certification examination. Prior to the first multidisciplinary discharge planning meeting, the hospital physician facilitator led an introductory meeting with the case

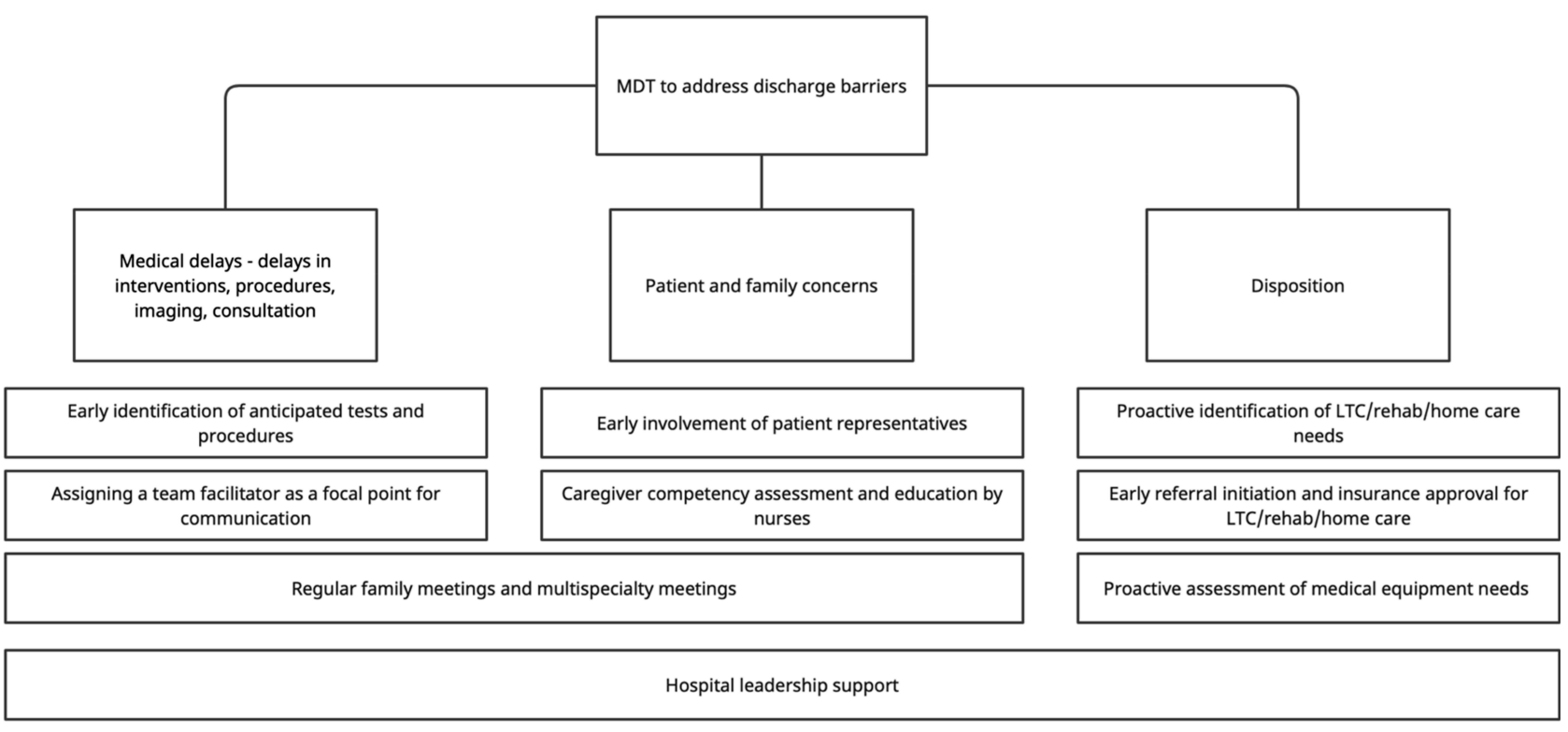

MDT: multi-disciplenary team LTC: long-term care

Figure I Multidisciplinary discharge coordination team intervention to address discharge barriers. 
managers to review the goals, process and structure of the meetings, and to outline their roles before, during and postmeetings.

One of the case managers conducted weekly screenings of all patients admitted to the general medicine wards for possible inclusion in the meetings. Patients were identified in 2 ways: length of stay exceeding average length of stay, based on diagnosis related group (DRG) for the admission diagnosis, or inpatients with cost of admission exceeding $80 \%$ of DRG payment for the admission diagnosis, as identified by the finance representative. DRGs are payment categories used to classify patients, based on diagnosis, complications and comorbidities, that are used to reimburse hospitals with a predetermined, fixed fee for each case in a given category, regardless of the actual treatment costs. ${ }^{18}$ Including the financial criteria helped to identify complex patients, who would likely need proactive discharge planning. The patient list was distributed one day prior to each meeting. All patients were eligible for inclusion, regardless of admission diagnosis or DRG.

A standard format was used during all meetings (Appendix 1). In addition to demographic information obtained from the electronic medical record (patient's name, medical record number, age, attending name, admission date, admission diagnosis and current length of stay), case managers collected information related to estimated discharge date, anticipated disposition, anticipated nursing or equipment needs, and details regarding family meetings and discussions. The standardized process ensured that complete information was discussed in a timely manner, and enabled all participants to provide their input.

\section{Activities of Multidisciplinary Discharge Coordination Team Addressing Medical Delays}

The discharge coordination team worked alongside the clinical team to identify anticipated tests and procedures and schedule them in a timely manner. When scheduling delays were encountered, the team facilitator personally communicated with the relevant imaging department or subspecialist. Unresolved issues were immediately escalated to hospital leadership during a scheduled weekly meeting. The Chief Medical Officer, or her designee, was often successful in expediting the test/procedure or subspecialty consult. This relieved clinical teams from the time and frustration of making frequent calls to follow up delays. Case managers on the team also scheduled multispecialty clinical meetings whenever different management plans or case discrepancies between subspecialty services were encountered. These face-to-face interactions have been shown to improve collaboration amongst clinical teams and improve the quality of care delivered. ${ }^{19}$

\section{Addressing Disposition Issues}

Case managers developed standardized processes for transfers to acute rehab and long-term care facilities. Referrals were made early during hospitalization, thus minimizing delays due to bed allocation. Insurance companies were proactively engaged. During regularly scheduled department meetings, billing representatives educated hospital clinicians about the documentation necessary for insurance approval. The potential need for durable medical equipment and home nursing services were also assessed early during hospitalization, and arrangements were made in a timely fashion. Follow up outpatient appointments were scheduled prior to discharge.

\section{Addressing Patient and Family Concerns}

Case managers were in frequent communication with family members regarding discharge plans. When disagreements arose regarding discharge dates, disposition, or goals of care, the team scheduled family meetings with the clinical teams to discuss all concerns. Patient representatives became involved early during hospitalization of patients with complex discharge needs to provide support. Charge nurses on the wards worked closely with families to help them gain caregiving competency (ie administer medications or feeding). 


\section{Impact of the Intervention}

We performed a retrospective observational study of all patients with delayed discharges from the general medicine service at SKMC from August 1, 2019 through December 31, 2019 and August 1, 2020 through December 31, 2020. COVID-19 cases were excluded. Of note, after the initial surge of COVID-19 admissions from February through June 2020, all patients with COVID-19 infection were admitted to a separate wing in the hospital and managed by a dedicated team of clinicians and case managers. Also, in the UAE, dedicated communicable disease hospitals managed the majority of hospitalized patients with COVID-19 infection. Through a search of the electronic medical record, we collected demographic data, principal diagnosis, discharge destination and length of stay, defined as the time from admission order to hospital discharge. We also measured emergency department visits requiring observation or inpatient admissions within 30 days of discharge. Descriptive statistics were used to calculate changes in variables before and postintervention.

To assess the perceptions of the multidisciplinary discharge coordination team intervention, a self-administered, anonymous survey was distributed online to all meeting participants. Survey participation was voluntary. Using a likert scale (strongly agree to strongly disagree), questions aimed to assess perceptions of the intervention, and its impact on patient outcomes and healthcare team satisfaction. Descriptive statistics were used to calculate frequencies.

Our multipronged approach was successful in decreasing length of stay in our delayed discharge patient population from 15.45 days to 9.04 days ( $\mathrm{p}<0.0001$ ), a 41.5\% reduction, without increasing 30-day readmission rates (Table 1 ).

Thirty-one of 34 participants responded to the survey ( $91.2 \%$ response rate). Overall, the healthcare team perceived the weekly multidisciplinary team meetings quite positively; approximately $90 \%$ of respondents agreed that the meetings improved communication and increased their sense of support. Table 2 lists participant responses.

Table I Patient Demographics and Outcomes Before and After Intervention

\begin{tabular}{|c|c|c|c|}
\hline Variable & Pre-Intervention & Post-Intervention & $p$ value \\
\hline Mean age (years) & 55 & 53 & \\
\hline Gender: Male & 764 (54\%) & $612(60 \%)$ & \\
\hline Female & 661 (46\%) & 407 (40\%) & \\
\hline \multicolumn{4}{|l|}{ Nationality } \\
\hline Arab Emirati & $620(43.5 \%)$ & $293(28.8 \%)$ & \\
\hline Arab & $46 I(32.4 \%)$ & $376(36.9 \%)$ & \\
\hline Asian & $292(20.5 \%)$ & $303(31.7 \%)$ & \\
\hline Other & $52(3.6 \%)$ & 47 (2.6\%) & \\
\hline \multicolumn{4}{|l|}{ Discharge disposition } \\
\hline Home & II 57 (8I.2\%) & $830(81.5 \%)$ & \\
\hline Long-term care facility & $3(0.2 \%)$ & $30(2.9 \%)$ & \\
\hline Other & 265 (18.6\%) & 159 (15.6\%) & \\
\hline \multicolumn{4}{|l|}{ Outcome } \\
\hline Total Discharges & 1425 & 1019 & \\
\hline 30-day readmission & 41 & 43 & $=0.17$ \\
\hline Average case-mix index & 2.05 & 2.34 & $<0.01$ \\
\hline Average length of stay & 15.45 & 9.04 & $<0.0001$ \\
\hline
\end{tabular}


Table 2 Survey Responses of Multidisciplinary Team Members

\begin{tabular}{|c|c|c|c|c|c|}
\hline Survey Respondents $(\mathrm{N}=3 \mathrm{I})$ & $\mathrm{n}(\% \mathrm{~N})$ & & & & \\
\hline Case manager & II (35.5\%) & & & & \\
\hline Hospital finance representative & I (3.2\%) & & & & \\
\hline Patient relations officer & I (3.2\%) & & & & \\
\hline Physician & $17(54.8 \%)$ & & & & \\
\hline Social worker & I (3.2\%) & & & & \\
\hline Survey Question $(\mathrm{N}=3 \mathrm{I})$ & $\begin{array}{l}\text { Strongly } \\
\text { Agree }\end{array}$ & Agree & $\begin{array}{l}\text { Neither Agree Nor } \\
\text { Disagree }\end{array}$ & Disagree & $\begin{array}{l}\text { Strongly } \\
\text { Disagree }\end{array}$ \\
\hline $\begin{array}{l}\text { The meetings increased communication among team } \\
\text { members }\end{array}$ & $19(61.3 \%)$ & $\begin{array}{l}9 \\
(29.0 \%)\end{array}$ & $2(6.5 \%)$ & 0 & I (3.2\%) \\
\hline $\begin{array}{l}\text { The meetings increased my sense of support from my } \\
\text { colleagues }\end{array}$ & $16(51.6 \%)$ & $\begin{array}{l}12 \\
(38.7 \%)\end{array}$ & $\mathrm{I}(3.2 \%)$ & I (3.2\%) & I (3.2\%) \\
\hline $\begin{array}{l}\text { The meetings increased my sense of support from hospital } \\
\text { leadership }\end{array}$ & $15(48.4 \%)$ & $\begin{array}{l}13 \\
(41.9 \%)\end{array}$ & $2(6.5 \%)$ & 0 & I (3.2\%) \\
\hline $\begin{array}{l}\text { The meetings helped me to better recognize and anticipate } \\
\text { discharge barriers }\end{array}$ & $15(48.4 \%)$ & $\begin{array}{l}13 \\
(41.9 \%)\end{array}$ & I (3.2\%) & I (3.2\%) & I (3.2\%) \\
\hline $\begin{array}{l}\text { The meetings were successful in addressing/removing } \\
\text { discharge barriers }\end{array}$ & $13(4 \mid .9 \%)$ & $\begin{array}{l}12 \\
(38.7 \%)\end{array}$ & $5(16.1 \%)$ & 0 & I (3.2\%) \\
\hline The meetings improved teamwork & $18(58.1 \%)$ & $\begin{array}{l}11 \\
(35.5 \%)\end{array}$ & 0 & I (3.2\%) & I (3.2\%) \\
\hline My opinions were respected during the meetings & $13(41.9 \%)$ & $\begin{array}{l}14 \\
(45.2 \%)\end{array}$ & $2(6.5 \%)$ & $\mathrm{I}(3.2 \%)$ & I (3.2\%) \\
\hline $\begin{array}{l}\text { The meetings promote a shared vision of proactive discharge } \\
\text { planning }\end{array}$ & 15 (48.4\%) & $\begin{array}{l}9 \\
(29.0 \%)\end{array}$ & $5(16.1 \%)$ & I (3.2\%) & I (3.2\%) \\
\hline
\end{tabular}

Note: Responses provided as $\mathrm{n}(\% \mathrm{~N})$.

\section{Implications and Conclusions}

Discharging patients from acute care hospitals is a complex process that requires coordination between patients and families and multidisciplinary teams. We implemented a multidisciplinary discharge coordination team with weekly team meetings to identify and address discharge barriers in patients with delayed discharge. Consistent with other studies, our results confirm the importance of system-level and multi-pronged approaches to overcome discharge delays. ${ }^{2,14}$ Our findings have several implications. First, although UAE hospitals routinely track length of stay, recognition of delayed discharges due to non-medical barriers can help identify inefficient processes and encourage interventions that improve discharge planning. Local data can also identify risk factors for prolonged hospitalization. ${ }^{20}$ Before the intervention, discharge planning in our department was not approached in a standard manner or addressed prior to the end of hospitalization.

Through this intervention, we learned that early and consistent engagement with the patient's family is critical to discharge success. Studies have noted that discharge planning interventions that included patient and family teaching components decrease hospital readmission rates. ${ }^{21}$ All clinical and administrative members of our care team communicated regularly with the patients and families, and initiated discharge planning conversations early during the hospitalization. These frequent interactions enable families to communicate their needs, so that arrangements can be made well in advance of medical readiness. This also ensures that patients leave the hospital prepared and ready for the transition, thereby reducing the likelihood of hospital readmission. ${ }^{9}$ 
Ragavan et al previously reported a framework of discharge barriers that encompassed eight categories, namely medical barriers, discharge planning, discharge site arrangement, patient and family coordination, pharmacy, postdischarge follow-up, goals of care, and medical reasons for delay. ${ }^{22}$ Intentionally addressing all of these issues is necessary to the development of a comprehensive discharge plan. We believe the success of our intervention was reliant on several important factors. First, the support from hospital leadership empowered the team to strengthen internal and external communication and collaboration. Next, the hard work and commitment of the case managers was invaluable to the project's success. The efficacy of the intervention depended on frequent meetings and diligent maintenance and updating of patient information. Since discharge needs and goals frequently change during hospitalization, the team needed to regularly reassess the appropriateness of the discharge plans, and revise accordingly. It is, therefore, reassuring that case manager perceptions of the intervention were overwhelmingly positive.

Our findings also confirmed that the physicians had positive perceptions of the intervention, despite the additional time investment for weekly meetings. Patients with delayed discharge are often more medically complex. The literature suggests that physicians prioritize acute clinical management over discharge planning. ${ }^{23}$ Yet, hospital physicians bear the burden of delayed discharges with increased patient census and workload. As such, hospital physicians, who were motivated by the opportunity to improve their daily workflow, led our discharge planning meetings. The use of a standardized format ensured that critical information was discussed, and facilitated communication between team members. Over the weeks, the meetings promoted positive teamwork and improved morale.

Our findings must be viewed in the light of several limitations. First, it was a single center study, thus limiting generalizability. Second, as a descriptive study, causation cannot be established, though our findings are consistent with other studies that have demonstrated that multidisciplinary discharge rounds can improve communication around discharge planning. ${ }^{2,24}$ Further, as a pre-post design, other factors could have affected our findings. For example, hospital-wide initiatives to improve inpatient length of stay, including development of a medical assessment unit, were also implemented during the same time period. This was the only intervention, however, to focus on complex discharge planning in patients with prolonged hospitalization. Also, our intervention took place during the COVID-19 pandemic. Although it was after the initial surge and patients with COVID-19 infection were hospitalized in a separate wing of the hospital, or in a different hospital altogether, and were excluded from this study, the pandemic renewed focus on bed utilization and resource management and changed the pace and urgency of hospital discharges. This may have contributed to some of the reductions in length of stay seen in our study. Finally, we did not involve other important members of the healthcare team, including clinical nurses and our medical residents, in the intervention. Previous studies promoting residents as physician leaders in discharge planning have shown success, but required repeated education sessions as new residents rotated onto the general medical ward. ${ }^{25}$ Integrating nurses and residents into the discharge planning team is an important next step.

In conclusion, delayed discharges put patients, healthcare workers and healthcare systems at risk for many adverse events. Multidisciplinary teams that integrate case coordinators and clinicians can improve communication and efficiency. Our project successfully improved hospital processes to overcome barriers to patient discharge. We believe that our intervention can be implemented in hospitals throughout the region to enhance collaboration and morale, and ultimately, to improve discharge coordination for hospitalized patients and their families. Future planned interventions include a program to continue contact with the patient and family post-discharge to review adherence to the discharge plan, address potential new concerns, and confirm follow up appointments.

\section{Abbreviations}

DRG, Diagnosis related group.

\section{Data Sharing Statement}

Data used in this study are available from the corresponding author upon reasonable request.

\section{Ethics Approval and Informed Consent}

The study was approved by the Sheikh Khalifa Medical City Research Ethics Committee (RS-726). 


\section{Consent for Publication}

Given the retrospective design of the study the waiver of informed consent was obtained from the Sheikh Khalifa Medical City Research Ethics Committee (RS-726).

\section{Acknowledgments}

The authors thank all SKMC case managers. This intervention would not have been successful without their hard work and commitment.

\section{Author Contributions}

All authors contributed to data analysis, drafting or revising the article, have agreed on the journal to which the article will be submitted, gave final approval of the version to be published, and agree to be accountable for all aspects of the work.

\section{Funding}

This research did not receive any specific grant from funding agencies in the public, commercial, or not-for-profit sectors.

\section{Disclosure}

The authors declare no competing interests.

\section{References}

1. Institute of Medicine. Crossing the Quality Chasm: A New Health System for the 21st Century. Washington, DC: National Academy Press; 2001.

2. Meo N, Liao JM, Reddy A. Hospitalized after medical readiness for discharge: a multidisciplinary quality improvement initiative to identify discharge barriers in general medicine patients. Am J Med Qual. 2020;35(1):23-28. doi:10.1177/1062860619846559

3. Sekjima A, Sunga C, Bann M. Adverse events experienced by patients hospitalized without definite medical acuity: a retrospective cohort study. $J$ Hosp Med. 2020;15(1):42-45. doi:10.12788/jhm.3235

4. Barnable A, Welsh D, Lundrigan E, Davis C. Analysis of the influencing factors associated with being designated alternate level of care. Home Health Care Manag Pract. 2015;27(1):3-12. doi:10.1177/1084822314539164

5. Mustafa F, Gilligan P, Obu D, et al. Delayed discharges and boarders: a 2-year study of the relationship between patients experiencing delayed discharges from an acute hospital and boarding of admitted patients in a crowded ED. Emerg Med J. 2016;33:636-640. doi:10.1136/emermed2015-205039

6. Basso O. Cost analysis of a system of ad hoc theatre sessions for the management of delayed trauma cases. J Orthop Traumatol. 2009;10(2):91-96. doi:10.1007/s10195-008-0042-2

7. Kuluski K, Im J, McGeown M. "It's a waiting game" a qualitative study of the experience of carers of patients who require an alternate level of care. BMC Health Serv Res. 2017;17(1):318. doi:10.1186/s12913-017-2272-6

8. Wilkerson M. Appropriate level of care: a patient flow, system integration and capacity solution; 2006. Available from: https://silo.tips/download/ appropriate-level-of-care-a-patient-flow-system-integration-and-capacity-solutio. Accessed October 5, 2021.

9. Arora VM, Prochaska ML, Farnan JM, et al. Problems after discharge and understanding of communication with their primary care physicians among hospitalized seniors: a mixed methods study. J Hosp Med. 2010;5(7):385-391. doi:10.1002/jhm.668

10. Hospital discharge delays 'cost NHS $£ 100$ m’. Health Serv J; 2014. Available from: https://www.hsj.co.uk/finance-and-efficiency/hospital-discharge -delays-cost-nhs-100m/5068992.article. Accessed September 14, 2021.

11. Mathews KS, Corso P, Bacon S, Jenq GY. Using the red/yellow/green discharge tool to improve the timeliness of hospital discharges. $J t$ Comm $J$ Qual Patient Saf. 2014;40(6):243-252. doi:10.1016/s1553-7250(14)40033-3

12. Schefft M, Lee C, Munoz J. Discharge criteria decrease variability and improve efficiency. Hosp Pediatr. 2020;10(4):318-324. doi:10.1542/ hpeds.2019-0244

13. Rojas-Garcia A, Turner S, Pizzo E, Hudson E, Thomas J, Raine R. Impact and experiences of delayed discharge: a mixed-studies systematic review. Health Expect. 2018;21(1):41-56. doi:10.1111/hex.12619

14. Meo N, Bann M, Sanchez M, Reddy A, Cornia PB. Getting unstuck: challenges and opportunities in caring for patients experiencing prolonged hospitalization while stable for discharge. Am J Med. 2020;133(12):1406-1410. doi:10.1016/j.amjmed.2020.05.024

15. Meo N, Paul E, Wilson C, Powers J, Magbual M, Miles KM. Introducing an electronic tracking tool into daily multidisciplinary discharge rounds on a medicine service: a quality improvement project to reduce length of stay. BMJ Open Qual. 2018;7(3):e000174. doi:10.1136/bmjoq-2017000174

16. Meo N, Cornia PB. Focusing on the medically ready for discharge patient using a reliable design strategy: a quality improvement project to improve length of stay on a medicine service. Qual Manag Health Care. 2021. doi:10.1097/QMH.0000000000000338

17. Koornneef E, Robben P, Blair I. Progress and outcomes of health systems reform in the United Arab Emirates: a systematic review. BMC Health Serv Res. 2017;17(1):672. doi:10.1186/s12913-017-2597-1

18. Rimler SB, Gale BD, Reede DL. Diagnosis-related groups and hospital inpatient federal reimbursement. Radiographics. 2015;35(6):1825-1834. doi:10.1148/rg.2015150043 
19. Epstein NE. Multidisciplinary in-hospital teams improve patient outcomes: a review. Surg Neurol Int. 2014;5(Suppl 8):S295-S303. doi:10.4103/ 2152-7806.139612

20. Osborne S, Harrison G, O’Malia A, Barnett AG, Carter HE, Graves N. Cohort study of a specialist social worker intervention on hospital use for patients at risk of long stay. BMJ Open. 2018;8(12):e023127. doi:10.1136/bmjopen-2018-023127

21. Jack BW, Chetty VK, Anthony D, et al. A reengineered hospital discharge program to decrease rehospitalization: a randomized trial. Ann Intern Med. 2009;150(3):178-187. doi:10.7326/0003-4819-150-3-200902030-00007

22. Ragavan MV, Svec D, Shieh L. Barriers to timely discharge from the general medicine service at an academic teaching hospital. Postgrad Med J. 2017;93(1103):528-533. doi:10.1136/postgradmedj-2016-134529

23. Berry JG, Blaine K, Rogers J, et al. A framework of pediatric hospital discharge care informed by legislation, research, and practice. JAMA Pediatr. 2014;168(10):955-962. doi:10.1001/jamapediatrics.2014.891

24. Patel H, Yirdaw E, Yu A, et al. Improving early discharge using a team-based structure for discharge multidisciplinary rounds. Prof Case Manag. 2019;24(2):83-89. doi:10.1097/NCM.0000000000000318

25. Goolsarran N, Olowo G, Ling Y, Abbasi S, Taub E, Teressa G. Outcomes of a resident-led early hospital discharge intervention. J Gen Intern Med. 2020;35(2):437-443. doi:10.1007/s11606-019-05563-w

Risk Management and Healthcare Policy

\section{Publish your work in this journal}

Risk Management and Healthcare Policy is an international, peer-reviewed, open access journal focusing on all aspects of public health, policy, and preventative measures to promote good health and improve morbidity and mortality in the population. The journal welcomes submitted papers covering original research, basic science, clinical \& epidemiological studies, reviews and evaluations, guidelines, expert opinion and commentary, case reports and extended reports. The manuscript management system is completely online and includes a very quick and fair peer-review system, which is all easy to use. Visit http://www.dovepress.com/testimonials.php to read real quotes from published authors.

Submit your manuscript here: https://www.dovepress.com/risk-management-and-healthcare-policy-journal 